\title{
Basic Dosage Form Category
}

National Cancer Institute

\section{Source}

National Cancer Institute. Basic Dosage Form Category. NCI Thesaurus. Code C150386.

A category of terms used to group together pharmaceutical dose forms. 